\title{
UNIVERSITYOF BIRMINGHAM

\section{Temporal trends in radiometrically dated sediment cores from English lakes show polybrominated diphenyl ethers correlate with brominated but not mixed bromo/chloro dioxins and furans}

Peters, Leon I.; Rose, Neil L.; Yang, Handong; Klánová, Jana; Moehring, Thomas; Harrad, Stuart

DOI:

10.1016/j.scitotenv.2020.143118

License:

Creative Commons: Attribution-NonCommercial-NoDerivs (CC BY-NC-ND)

Document Version

Peer reviewed version

Citation for published version (Harvard):

Peters, LI, Rose, NL, Yang, H, Klánová, J, Moehring, T \& Harrad, S 2021, 'Temporal trends in radiometrically dated sediment cores from English lakes show polybrominated diphenyl ethers correlate with brominated but not mixed bromo/chloro dioxins and furans', Science of the Total Environment, vol. 762, 143118.

https://doi.org/10.1016/j.scitotenv.2020.143118

Link to publication on Research at Birmingham portal

\begin{abstract}
General rights
Unless a licence is specified above, all rights (including copyright and moral rights) in this document are retained by the authors and/or the copyright holders. The express permission of the copyright holder must be obtained for any use of this material other than for purposes permitted by law.
\end{abstract}

- Users may freely distribute the URL that is used to identify this publication.

- Users may download and/or print one copy of the publication from the University of Birmingham research portal for the purpose of private study or non-commercial research.

- User may use extracts from the document in line with the concept of 'fair dealing' under the Copyright, Designs and Patents Act 1988 (?)

- Users may not further distribute the material nor use it for the purposes of commercial gain.

Where a licence is displayed above, please note the terms and conditions of the licence govern your use of this document.

When citing, please reference the published version.

Take down policy

While the University of Birmingham exercises care and attention in making items available there are rare occasions when an item has been uploaded in error or has been deemed to be commercially or otherwise sensitive.

If you believe that this is the case for this document, please contact UBIRA@lists.bham.ac.uk providing details and we will remove access to the work immediately and investigate. 
1 Temporal Trends in Radiometrically Dated Sediment Cores

2 from English Lakes Show Polybrominated Diphenyl Ethers

3 Correlate with Brominated but not Mixed Bromo/Chloro

\section{Dioxins and Furans}

5

Leon I. Peters ${ }^{\mathrm{a} \#}$, Neil L. Rose ${ }^{\mathrm{b}}$, Handong Yang ${ }^{\mathrm{b}}$, Jana Klánovác ${ }^{\mathrm{c}}$, Thomas Moehring ${ }^{\mathrm{d}}$, Stuart

9 aSchool of Geography, Earth, and Environmental Sciences, University of Birmingham,

10 Birmingham, B15 2TT, U.K.

$11{ }^{b}$ Environmental Change Research Centre, Department of Geography, University College London,

12 London, WC1E 6BT, U.K.

$13{ }^{\mathrm{c}}$ RECETOX, Masaryk University, Brno, Czech Republic

$14{ }^{\mathrm{d}}$ Thermo Fisher Scientific $(\mathrm{GmbH})$ Bremen, Hanna-Kunath-Str. 11, 28199 Bremen, Germany 15

$16{ }^{*}$ Deceased

17 *Email address: S.J.Harrad@bham.ac.uk 


\section{ABSTRACT}

20 This paper reports concentrations between $\sim 1950$ and present, of polybrominated diphenyl ethers

21 (PBDEs) and polybrominated dibenzo-p-dioxins and furans (PBDD/Fs), in radiometrically-dated

22 sediment cores from three English lakes. Mixed bromo/chloro dibenzo-p-dioxins and furans

$23(\mathrm{PXDD} / \mathrm{Fs})$ were measured in two of the same lakes. Concentrations of PXDD/Fs decreased over

24 time to the present. To our knowledge, this is the first report of temporal trends of PXDD/Fs in the

25 environment. In contrast, concentrations of PBDEs increased towards the present and were

26 significantly correlated $(\mathrm{R}=0.88-0.98 ; \mathrm{p}<0.05)$ with concentrations of PBDFs in all three lakes.

27 These observations suggest that the sources of PXDD/Fs are not related to PBDEs and differ from

28 those of PBDFs. We also report for the first time the presence of octabromodibenzofuran (OBDF)

29 in the two most recent core slices at one lake. The source of OBDF in these samples is unclear.

30 While OBDF has been reported previously as a significant contaminant of some commercial

31 formulations of Deca-BDE, it is also present in Octa-BDE products and in emissions from a variety

32 of combustion activities. Overall, while the positive correlation between PBDEs and PBDFs

33 suggests increased use of PBDEs has contributed substantially to environmental contamination

34 with PBDFs; examination of PBDF homologue patterns implies emissions from combustion

35 activities are likely also important. 
Keywords

37 PBDD/Fs; PXDD/Fs; PBDEs; Time Trends; Sources; Lakes 


\section{Introduction}

Polybrominated diphenyl ethers (PBDEs) are industrial chemicals that have found extensive global use as flame retardants added to a wide range of consumer items such as electrical and electronic equipment and furniture fabrics and foams. As a consequence of their environmental persistence, potential for long-range atmospheric transport and bioaccumulation, and adverse effects on humans and/or wildlife, PBDEs are listed under the United Nations Environment Program's Stockholm Convention on Persistent Organic Pollutants (POPs). Moreover, manufacture and new use of PBDEs is either banned or restricted by many jurisdictions. Against this backdrop, there is a clear need to evaluate the efficacy of such actions; for example, by monitoring temporal trends in environmental contamination. Several studies worldwide have previously delineated the increase in concentrations of PBDEs in the environment from the onset of their widespread use in the 1980s to mid-2000s when the first restrictions on them were introduced (Kohler et al, 2008; Zegers et al, 2003; Vane et al, 2010; Webster et al, 2008). Subsequent trends up to the present, point to concentrations levelling off and even declining as actions to eliminate PBDEs take effect (Yang et al, 2016). One concern with respect to PBDEs is that commercial PBDE products have been shown to contain polybrominated dibenzo-p-dioxins and furans (PBDD/Fs) as contaminants at levels that amount to a substantial mass (0.43 - $2.2 \mathrm{t}$ globally) of PBDD/Fs (Hanari et al, 2006; Ren et al, 2011). This is consistent with a recent report that temporal trends of PBDFs correlate with those of PBDEs in sediment cores from Tokyo Bay (Goto et al, 2017). This is concerning owing to evidence of the toxicity of PBDFs that is considered by the WHO to be on a par with that of their chlorinated analogs (Van den Berg et al, 2013). Moreover, there exists emerging concern about environmental contamination with mixed bromo-/chloro-dibenzo-p-dioxins and furans (PXDD/Fs) (Wall et al, 2015). Although little is known about the toxicity of PXDD/Fs, their structural similarity to 
$61 \mathrm{PBDD} /$ Fs means that establishing the level at which they are present in the environment and elucidating their sources is desirable. Studies exist that demonstrate that combustion activities such as iron ore sintering and waste incineration are sources of PXDD/Fs (Chatkittikunwong and Creaser, 1994; Weber et al, 2003), with their presence in air in Japan (Hayakawa et al, 2004) as well as soil impacted by a recycling plant fire (Myers et al, 2012) and by informal e-waste handling reported (Leung et al, 2007; Ma et al, 2008; Tue et al, 2013; Yu et al, 2008; Zennegg et al, 2009). Currently however, very few data exist on concentrations of $\mathrm{PXDD} / \mathrm{Fs}$ in sediments. Concentrations of $\Sigma \mathrm{PXDD} / \mathrm{Fs}$ were between $0.03-0.1 \mathrm{ng} / \mathrm{g}$ dry weight in freshwater sediment taken from a former chlor-alkali plant in the USA, with monobromoheptachloro dibenzo-p-dioxin the only congener detected (Kannan et al, 1998). In Osaka Bay, Japan, a wider range of PXDD/Fs were detected in marine sediment, most prominently 2-Br-3,7,8-ClCDD detected between 0.84-6.5 pg/g dry weight (Ohta et al, 2002), while concentrations of monobromo-polychlorinated dibenzo-p-dioxins/dibenzofurans which ranged between below detection limit and $1.8 \mathrm{ng} / \mathrm{g}$ dry weight were reported for marine surficial sediments from Hong Kong and Korea (Terauchi et al, 2009).

In this study we exploit the fact that sediment deposited in lakes over time can provide a reliable record of contaminant inputs into lacustrine systems. We thus collected sediment cores from three English lakes for which data on concentrations of PBDEs, hexabromocyclododecane (HBCDD), and polychlorinated biphenyls (PCBs) have been measured previously (Yang et al, 2016) and used radiometric techniques to assign dates to core slices representing different depths. Concentrations of PBDEs, PBDD/Fs, and PXDD/Fs were measured in individual core slices and the data used to test the hypothesis that these contaminant classes will display similar temporal trends.

\section{Experimental}




\subsection{Sampling locations}

A map of our sampling locations is given as supplementary data (Figure SD-1), with additional information about individual sites supplied in Table SD-1. Locations studied were 3 of the same seepage lakes for which we have previously reported temporal trends in concentrations of PBDEs, HBCDD, and PCBs in sediment cores (Yang et al, 2016). These were: Edgbaston Pool, Holt Hall Lake, and Wake Valley Pond. These lakes were selected from locations with a range of population densities as a surrogate indicator of anthropogenic inputs. One sediment core from each lake was collected between $23^{\text {rd }}-26^{\text {th }}$ June 2015 , covering sedimentation from at least $\sim 1950$ to the date of sampling. Consistent with our previous study of these lakes (Yang et al, 2016), each core was collected from a flat area of the lake basin near the deepest point.

\subsection{Sampling and sectioning of lake sediment cores}

Cores were sampled from a flat area close to the maximum depth at each site and were collected from a purpose built pontoon to a depth of between $0.75-0.95 \mathrm{~m}$ below the benthic surface using a large diameter sediment core apparatus ('Big-Ben') (Patmore et al, 2014). The sediment corer, piston and core covers were all thoroughly decontaminated with hexane before and after use. The 'Big-Ben' corer having an internal diameter of $140 \mathrm{~mm}$, is considerably larger than conventional piston corers (typically 50 - $80 \mathrm{~mm}$ i.d.) and provides sediment cores with a cross-sectional area of $154 \mathrm{~cm}^{2}$ resulting in far greater sample for analysis, and facilitating the analysis of PBDD/Fs and PXDD/Fs at the anticipated ultra-trace levels. Sediment cores were extruded vertically in the field at $10 \mathrm{~mm}$ intervals, with each sample stored at $-20^{\circ} \mathrm{C}$ in individually sealed Whirl-Pack ${ }^{\mathrm{TM}}$ sampling bags until extraction analysis. Sample contamination derived from use of Whirl-Pack ${ }^{\mathrm{TM}}$ sampling bags manufactured from low density polyethylene (LDPE) was controlled for with the use of sampling blanks, which consisted of $30 \mathrm{~g}$ pre- cleaned $\mathrm{Na}_{2} \mathrm{SO}_{4}$ spiked with $10 \mu \mathrm{L}$ 
${ }^{13} \mathrm{C}_{12}$-BDE-138. Sampling control blanks were opened to the atmosphere for approximately $30 \mathrm{~min}$

108 to allow the sampling spike solvent to evaporate, before being homogenised and sealed until

109 analysis. Three sampling blanks were employed per site and treated analogously to sediment

110 samples, including extraction and analysis. Recoveries of ${ }^{13} \mathrm{C}_{12}$-BDE-138 ranged between $50-110$

$111 \%$ with a mean of $85.4 \pm 35.2 \%($ Mean $\pm 1 \mathrm{SD})$ and all cases $(\mathrm{n}=9)$ yielded BFR concentrations

112 below limits of quantification confirming that the sample collection procedure did not contribute to

113 sediment contamination with PBDEs.

114 Each sediment sample was divided into two during the core-sectioning procedure: two thirds kept

115 for analysis of our target contaminants; with the remaining one third used for radiometric dating

116 and determination of sediment water and total organic carbon (TOC) content. The latter two

117 metrics were determined gravimetrically by mass loss from a $2 \mathrm{~g}$ (wet weight) sample, oven dried

118 at $105^{\circ} \mathrm{C}$ for $3 \mathrm{~h}$ to determine water content and a further $2 \mathrm{~h}$ at $550{ }^{\circ} \mathrm{C}$ to determine TOC by

119 loss-on-ignition. After freeze-drying, each $10 \mathrm{~mm}$ core slice was homogenized. Thereafter, based

120 on information from our radiometric dating results, we combined $10 \mathrm{~mm}$ core slices from the same

121 core to generate a series of pooled core slice samples that each represented around five years of

122 sedimented material. In total, 31 such pooled samples were prepared for analysis. A further core

123 slice was analyzed from the bottom of the core taken from each of our lakes, to provide an

124 indication of concentrations of our target contaminants prior to $\sim 1950$.

\section{Analytical methods}

126 Details of methods used to radiometrically date (using ${ }^{210} \mathrm{~Pb}$ ) sediment core slices are given as SD,

127 with sediment chronologies and sedimentation rates provided as Tables SD-2-SD-4 and Figures

128 SD-2-SD-7. For determination of concentrations of target contaminants in sediment samples, $5 \mathrm{~g}$

129 each of both hydromatrix and sodium sulfate (both pre-cleaned) were loaded into pre-cleaned 
stainless steel extraction cells, along with an aliquot of freeze-dried and homogenized sediment core slice (typically $5 \mathrm{~g}$, accurately weighed). This was treated with ${ }^{13} \mathrm{C}$-labeled internal standards (details below) and subjected to pressurized liquid extraction using an ASE-350 (Dionex, CA). Extraction was first with hexane:dichloromethane (3:2, v/v; 2 cycles), followed by toluene ( 2 cycles) at $90^{\circ} \mathrm{C}, 1500 \mathrm{psi}$ and hold time $=5 \mathrm{~min}$. Following concentration to $\sim 1 \mathrm{~mL}$ using a Turbovap solvent evaporator, crude sediment extracts were purified prior to instrumental analysis via elution through a sequence of acid silica and activated carbon columns (Cape Technologies, Maine, USA). This yielded two concentrated extracts (F1b and F2b) for instrumental analysis of PBDEs (F1b) and PBDD/Fs + PXDD/Fs (F2b) for each sediment core slice. Detailed descriptions of the complex procedures used to purify and fractionate sediment core extracts prior to instrumental analysis are provided as SD (Figures SD-8-10 and accompanying text).

Commercially available standards were used for the analysis of BFRs. These comprised native PBDEs and ${ }^{13} \mathrm{C}_{12}$-BDEs 28, 47, 99, 100, 153, 154, 183, 207, and 209 (Wellington Laboratories) and native and ${ }^{13} \mathrm{C}_{12}$ - analogues of the following PBDD/Fs (Cambridge Isotope Laboratories): 2,3,7,8-TBDD, 1,2,3,7,8-PeBDD, 1,2,3,4,7,8-HxBDD, 1,2,3,6,7,8-HxBDD, 1,2,3,7,8,9-HxBDD, 1,2,3,4,6,7,8-HpBDD, OBDD, 2,3,7,8-TBDF, 2,4,6,8-TBDF, 1,2,3,7,8-PeBDF, 2,3,4,7,8-PBDF, 1,2,3,4,7,8-HxBDF, 1,2,3,4,6,7,8-HpBDF, and OBDF. The following native standards of PXDD/Fs were kindly provided by Dr. Alwyn Fernandes, FERA, UK: 2-Br-7,8-CDD, 2-Br-3,7,8-CDD, 2,3-Br-7,8-CDD, 1-Br-2,3,7,8-CDD+2-Br-1,3,7,8-CDD, 2-Br-3,6,7,8,9-CDD, 2-Br-7,8-CDF, 2-Br-6,7,8-CDF+3-Br,2,7,8-CDF, and 1-Br-2,3,7,8-CDF. In the absence of ${ }^{13} \mathrm{C}_{12}$-labeled PXDD/Fs, ${ }^{13} \mathrm{C}_{12}-2,4,6,8$-TBDF was used as internal (surrogate) standard for quantification of PBDD/Fs.

\section{Instrumental Analysis}


153 Quantification of target compounds and congener groups was conducted on a Thermo Scientific

154 GC Q Exactive GC/orbitrap MS. Concentrations of PBDEs were determined via injection of $2 \mu \mathrm{L}$ 155 of F1 onto a Thermo Fisher Scientific Trace Gold Dioxin capillary column (12 m x $0.25 \mathrm{~mm}$ x 0.1

$156 \mu \mathrm{m}$ ), with the GC-MS operated in selected ion monitoring (SIM) mode. Concentrations of

$157 \mathrm{PBDD} / \mathrm{Fs}$ and PXDD/Fs were determined by injecting $2 \mu \mathrm{L}$ of F2 onto the same GC column, with 158 the GC-MS operated in full scan mode. For both F1 and F2, extracts were injected via a PTV

159 injector operating in splitless mode. A programmed temperature of injection of $120^{\circ} \mathrm{C}$ followed by 160 a ramp profile from $150{ }^{\circ} \mathrm{C}$ to $320^{\circ} \mathrm{C}$ at $14.5^{\circ} \mathrm{C} / \mathrm{sec}$ was deployed. A constant He flow of 1.3

$161 \mathrm{~mL} / \mathrm{min}$ was deployed with a temperature program of: $120^{\circ} \mathrm{C}$ held for $3 \mathrm{~min}$ before ramping to 250

$162{ }^{\circ} \mathrm{C}$ at $6.5^{\circ} \mathrm{C} / \mathrm{min}$, followed by a second ramp from $250{ }^{\circ} \mathrm{C}$ to $305^{\circ} \mathrm{C}$ at $8{ }^{\circ} \mathrm{C} / \mathrm{min}$ held for $7 \mathrm{~min}$. The

163 orbitrap MS was operated at 60,000 mass resolution, which facilitated confirmation of analyte

164 identity via accurate mass. In all cases, where a standard for a given compound was included in our 165 calibration standard, identification of that compound was via comparison of retention time to the 166 standard, while quantification of that compound was made using its response factor relative to the 167 appropriate internal (surrogate) standard. For PBDD/F and PXDD/F compounds for which we did 168 not have standards, quantification was achieved using an averaged relative response factor for

169 compounds of the same homologue group. For example, hexabromo-PBDFs were quantified using 170 the relative response factor for $1,2,3,4,7,8-\mathrm{HxBDF}$. Full details of mass spectrometric parameters 171 are provided as SD.

$172 \quad Q A / Q C$

173 Recoveries for all target analyte internal standards ranged between 50 and $110 \%$, with the 174 exception of ${ }^{13} \mathrm{C}_{12}$-OBDD and ${ }^{13} \mathrm{C}_{12}$-OBDF for which recoveries in some samples were as low as $17540 \%$. Method accuracy was assessed for PBDEs by replicate $(n=7)$ analysis of NIST SRM1944 
176 (New York/ New Jersey Waterway Sediment). This revealed good agreement between

177 concentrations measured in this study with the certified values reported by NIST. Full details are

178 provided in SD (Table SD-5). While certified or indicative values have not previously been

179 reported for PBDD/Fs and PXDD/Fs, they are also provided as SD (Tables SD-6 and SD-7) for

180 comparison with future studies.

$181 \quad$ Statistical methods

182 All statistics in this study were conducted using IBM SPSS Statistics 21, and Microsoft Excel

1832007.

\section{Results and discussion}

185 Concentrations of PBDEs

186 Concentrations of all target PBDEs and PBDD/Fs in each individual core slice from each sampling

187 location are provided as supporting data (Tables SD-8 - SD-13). Table 1 provides a summary of

188 concentrations of $\Sigma$ PBDEs detected in this study together with those reported in selected relevant

189 previous studies for comparison. Most pertinently, concentrations of $\Sigma$ PBDEs reported for surficial

190 sediments for our three lakes match closely with those reported previously by our group for

191 surficial sediments (albeit dating from 6-7 years earlier) for the same lakes (Yang et al, 2016).

192 While the lake situated in the local authority with the highest population density (Edgbaston Pool)

193 displayed the greatest concentrations of SPBDEs, concentrations at Wake Valley Pond and Holt

194 Hall Lake are similar despite Wake Valley Pond being located in a more densely populated local

195 authority area (Table SD-1 - i.e. Edgbaston Pool 2,500 people $/ \mathrm{km}^{2}>$ Wake Valley Pond 250-499

196 people $/ \mathrm{km}^{2}>$ Holt Hall Lake $100-249$ people $/ \mathrm{km}^{2}$ ). This is partly consistent with previous findings

197 showing higher concentrations of PBDEs in air and soil from more densely populated areas due to 
emissions from the built environment (Harrad and Hunter, 2006). Concentrations of $\Sigma$ PBDEs in this study at Edgbaston Pool ca $3 \mathrm{~km}$ from the center of the city of Birmingham are close to the average reported for surficial sediments collected in 2011 from 45 locations along the River Thames in the UK (Ganci et al, 2019). By comparison, those at Holt Hall Lake and Wake Valley Pond are around an order of magnitude lower than at Edgbaston Pool. When compared to $\Sigma$ PBDE concentrations in surficial sediments collected in 2002-2003 as part of two studies conducted in industrial areas of the River Clyde in Scotland (Vane et al, 2010; Webster et al, 2008), concentrations at all three lakes in our study are substantially lower.

\section{Relative Abundance of PBDE Congeners}

The PBDE congener pattern in all our samples is dominated by BDE-209. This is consistent with industry figures that in Europe, Deca-BDE production far exceeded that of both Penta- and Octa-BDE (BSEF, 2003). It is also in line with previous reports for the same lakes (Yang et al, 2016), with sediment cores from the Clyde Estuary in Scotland, UK (Vane et al, 2010; Webster et al, 2008), and with surficial sediments from the River Thames running through London, UK (Ganci et al, 2019). Consistent with the Clyde Estuary, the relative contribution of the nona-BDEs-206, -207, and -208 to $\Sigma$ PBDEs in this study exceeds that observed in commercial formulations of Deca-BDE. Specifically, in the top three core slices from all three locations, $\Sigma$ nona-BDEs comprises $8-27 \%$ of $\Sigma$ BDEs. This compares to 2.5 and $9.3 \%$ respectively in the commercial Deca-BDE formulations Saytex 102E and Bromkal 82-0DE (La Guardia et al, 2006). While the contribution of $\Sigma$ nona-BDEs to $\Sigma$ BDEs is higher in the commercial Octa-BDE products DE-79 and Bromkal 79-8DE at 12.1 and $18.9 \%$ respectively (La Guardia et al, 2006); the contribution of the main indicator congener for Octa-BDE (BDE-183) to $\Sigma$ PBDEs in our sediments is much lower $(0.45-2.1 \%$ in the top three slices at all lakes) than in DE-79 and Bromkal $79-8 \mathrm{DE}(42 \%$ and $12.6 \%$ 
respectively). On this evidence, the presence of the three nona-BDEs in this study seem most likely attributable to debromination of BDE-209. This is supported by the fact that BDE-209 and Enona-BDEs are positively correlated $(\mathrm{p}<0.05$ at Edgbaston Pool; $\mathrm{p}<0.1$ at Wake Valley Pond and Holt Hall Lake) at each lake studied here. Similar conclusions were drawn based on the observation that nona-BDEs were the second most abundant homologue group after BDE-209 in river sediments from China (Mai et al, 2005; Zhang et al, 2009). However, we note a report of elevated abundances of BDE-208 relative to BDE-209 in TV/PC display casings, and PC components sampled in South China. In this study the authors attributed to the decomposition of higher brominated PBDEs during the process of manufacturing use and/or recycling of PBDE-containing products (Chen et al., 2010). Specifically, the ratios of average concentrations of BDE-208: average concentrations of BDE-209 in TV and PC housing were 5.4\% and 2.8\% respectively. By comparison, BDE-208:BDE-209 ratios in the uppermost 4 core slices in our study ranged from $0.2 \%$ to $0.6 \%$ at Edgbaston Pool; $1.3 \%$ to $2.0 \%$ at Wake Valley Pond; and $1.3 \%$ to $9.5 \%$ at Holt Hall Lake. It is thus possible that the nona-BDEs detected in our study have arisen at least in part to emissions from treated products as well as any post-emission

236 debromination (Law et al., 2008).

\section{Temporal Trends in PBDEs in English Lake Sediments}

238 Figure 1 plots the temporal trends in concentrations of $\Sigma$ PBDEs at all three locations. Given the 239 predominant contribution of BDE-209 to $\Sigma$ PBDEs, the trends in $\Sigma$ PBDEs reflect those of 240 BDE-209. Importantly, BDE-209 concentrations in the cores from Edgbaston Pool and Wake 241 Valley Pond do not peak in the uppermost core slice (2015); instead the highest concentrations are 242 found in the slice immediately below (2012 and 2009 for Edgbaston Pool and Wake Valley Pond 243 respectively). The situation differs for Holt Hall Lake, where the highest BDE-209 concentration is 
244 in the surficial sediment (2015). Overall, this suggests that while the full impact of recent

245 restrictions on the manufacture and use of Deca-BDE has yet to manifest itself at the lakes studied

246 here; there are tentatively encouraging signs that contamination is levelling off.

247 Concentrations, Relative Abundance, and Possible Sources of PBDD/Fs in English Lake

248 Sediments

$249 \mathrm{PBDD} /$ Fs were detected in all samples in this study at concentrations two orders of magnitude

250 below those of PBDEs. Table 1 compares $\Sigma$ PBDD/F concentrations in this study compared to those 251 reported in a variety of previous studies from other locations. Concentrations in sediment core 252 slices from the less urbanised Wake Valley Pond and Holt Hall Lake are in line with those reported 253 for Swedish lakes and rivers (Hagberg et al, 2005; Lundstedt, 2016). However, those at Edgbaston 254 Pool exceed those reported elsewhere. Similar to the situation for PBDEs, while the lake situated in 255 the local authority with the highest population density (Edgbaston Pool) has noticeably the highest $256 \Sigma \mathrm{PBDD} / \mathrm{F}$ concentrations; levels of these contaminants are similar at Wake Valley Pond and Holt 257 Hall Lake despite the former being located in a more densely populated local authority area.

258 PBDFs were overwhelmingly dominant, with OBDD the only PBDD detected and that only in the 259 uppermost two layers in the cores taken at Wake Valley Pond and Holt Hall Lake. This is 260 consistent with previous observations for surficial sediments and atmospheric deposition (Goto et 261 al, 2017; Hayakawa et al, 2004), as well as in emissions from waste incinerators (Wang et al, 262 2010), and iron ore sintering (Drage et al, 2014). It is also pertinent to note that while OBDD and to 263 a far lesser extent penta- and tetra-BDDs have been detected in commercial PBDE formulations 264 (Ren et al, 2011), PBDFs - especially OBDF and 1,2,3,4,6,7,8-HpBDF - were in comparison 265 detected in such products at far higher concentrations (Hanari et al, 2006; Ren et al, 2011). 
Figure 2 shows the homologue profiles of PBDFs in sediment core slices from each lake. It is interesting to note the spatial variation in these profiles, for example TBDFs are far less abundant at Edgbaston Pool than at the other two lakes. A striking observation is that OBDF was detected at Wake Valley Pond - albeit only in the two uppermost core slices (2015 and 2009). To our knowledge, this is the first report of OBDF in sediments. The low detection frequency of OBDF in sediments is perhaps surprising given previous data that reports OBDF to be an impurity in both

272 Octa-BDE and Deca-BDE commercial formulations (Hanari et al, 2006; Ren et al, 2011).

273 However, this may be because OBDF has been reported to be easily debrominated (Goto et al, 274 2017). Overall, the PBDF homologue pattern in our sediment cores (expressed as a percentage of $275 \Sigma$ PBDFs) more closely resembles that reported for the Octa-BDE formulation which comprises 0.3 \% TBDFs, $1.8 \%$ PeBDFs, $44.9 \%$ HxBDFs, $27.1 \%$ HpBDFs, and $25.8 \%$ OBDF, than the Deca-BDE formulation which comprises $0.1 \%$ for each of TBDFs, PeBDFs, and HxBDFs, 3.6\% for HpBDFs, and 96.1\% OBDF. While this might suggest the Octa-BDE commercial formulation is a more significant source of the PBDFs observed in our sediments than the Deca-BDE product; as noted above, the major PBDE formulation used in the UK was Deca-BDE. Moreover, we note

281 that concentrations of $\Sigma$ PBDFs are more strongly correlated with those of BDE-209 $(\mathrm{R}=0.96$, $282 \mathrm{p}<0.05$ and $\mathrm{R}=0.85, \mathrm{p}<0.1)$ than those of BDE-183 at both Edgbaston Pool and Wake Valley Pond $283(\mathrm{R}=0.48, \mathrm{p}>0.1$ and $\mathrm{R}=0.64, \mathrm{p}>0.1)-$ no meaningful inference could be drawn in this regard at Holt 284 Hall Lake as there were too few samples in which PBDFs and both BDEs-183 and -209 were 285 detected.

286 In addition to the potential contribution of PBDE use, both OBDF and 1,2,3,4,6,7,8-HpBDF (the 287 predominant HpBDF detected in this study) have been reported to be emitted from combustion 288 processes (Wang et al, 2015). We also note that we did not target 

identified as being of biogenic origin (Goto et al, 2017) and can therefore not rule out possible contributions from biogenic sources to the burden of PBDD/Fs in our lakes. In summary, drawing

292 firm conclusions about PBDD/F source attribution based on homologue and congener patterns in environmental matrices like lake sediments, is complicated by post-emission modification of such profiles by weathering processes that favour some PBDD/Fs more than others. Notwithstanding this, the evidence of congener/homologue profiles presented here, suggests that the PBDD/Fs detected in this study are predominantly a complex integral of combustion source emissions and 297 their presence as contaminants of the Deca-BDE formulation. \\ Temporal Trends in concentrations of $\triangle \mathrm{PBDF}$ and PBDF homologue patterns}

299 Temporal trends in concentrations of $\Sigma$ PBDFs are shown in Figure 1. Overall, they reveal a steady 300 rise in concentrations from the 1980s onwards, peaking at the surface (2015) at Edgbaston Pool and 301 Wake Valley Pond, and in the second most recent core slice (dated to 2009) at Holt Hall Lake. Prior 302 to the onset of rising concentrations in the 1980s, concentrations were much lower. Inspection of 303 Figure 1 suggests temporal trends in $\Sigma$ PBDEs and $\Sigma$ PBDFs are positively correlated and indeed the correlation coefficient for the three sites is significant, ranging between $0.88-0.98(\mathrm{p}<0.05$ at each site). With respect to changes in the homologue pattern over time, Figure 2 reveals no clear trend at Holt Hall Lake. In contrast, there is a marked shift from HpBDFs to HxBDFs in more recent

307 sediment layers at Edgbaston Pool. Meanwhile at Wake Valley Pond, there is a noticeable decline 308 in the abundance of TBDFs, along with increased abundance of HpBDFs in more recent core 309 slices, as well as the aforementioned presence of OBDF in the top two layers (dated to 2009 and 3102015 ) only. These variable homologue patterns and temporal trends suggest that changes in the 311 relative contributions of different sources of PBDFs over time differ between our three lakes. To 
our knowledge there is only one study with which our data on PBDF homologue patterns in sediment cores can be compared. In this study of a sediment core from Osaka Bay in Japan that covered the period 1904-2000, OBDF was not detected and in declining order of abundance the other homologues followed the order HpBDF $>$ HxBDF $>$ PeBDF $>$ TBDF (Takigami et al, 2005). This homologue pattern most closely resembled that observed in this study at Holt Hall Lake.

\section{Concentrations, Relative Abundance, and Temporal Trends of PXDD/Fs in English Lake}

\section{Sediments}

Table 2 reports concentrations of individual PXDD/Fs and homologue groups in each sediment core slice analyzed in this study. Also included in Table 2 are concentrations of 2-Br-3,7,8-CDD, 2-Br-3,6,7,8,9-CDD, 2-Br-2,7,8-CDF, and 1-Br-2,3,7,8-CDF reported previously in surficial sediments collected from Osaka Bay, Japan (Ohta et al, 2002). Concentrations of these PXDD/Fs in our study are of a similar range to those reported for Osaka Bay. As observed for both PBDEs and PBDD/Fs, concentrations of $\Sigma \mathrm{PXDD} / \mathrm{Fs}$ at the two lakes studied for these contaminants do not correspond with the population density of the local authority within which the lake was submitted (Table SD-1). Specifically, t-test comparison shows PXDD/F concentrations at Wake Valley Pond to be statistically indistinguishable $(\mathrm{p}>0.05)$ from those at Holt Hall Lake. For PXDD/Fs, the concentrations detected were typically two orders of magnitude below those of PBDD/Fs. PXDFs were more abundant than PXDDs in every core slice analysed from both locations where PXDD/Fs were determined, with PXDFs typically 2-3 times more abundant. There was no clear temporal trend in the ratio of PXDFs:PXDDs at either lake. Moreover, the homologue pattern is broadly similar at both lakes and does not appear subject to temporal variation. 
334 Temporal trends in concentrations of PXDD/Fs differ between the two lakes in which they were

335 measured. Concentrations at Wake Valley Pond peak in the oldest slice (1954) analyzed at this

336 location and then steadily decrease through to the present (2015). In slight contrast, concentrations

337 at Holt Hall Lake rise from 1935 to 1976, before declining through to the uppermost layer (2015).

338 In contrast to the significant positive correlation between $\Sigma$ PBDEs and $\Sigma$ PBDFs at all three lakes, 339 concentrations of $\Sigma$ PBDEs are not significantly correlated $(p>0.05)$ with those of $\Sigma$ PXDD/Fs.

340 Likewise, $\Sigma \mathrm{PBDD} / \mathrm{Fs}$ are not correlated with $\Sigma \mathrm{PXDD} / \mathrm{Fs}(\mathrm{p}>0.05)$. Overall, this suggests that the 341 sources of PXDD/Fs are different to those of PBDD/Fs, and that the manufacture and use of 342 PBDEs does not appear to be a source of PXDD/Fs.

\section{Conclusions}

345 Concentrations of PXDD/Fs in radiometrically-dated sediment cores from 3 English lakes 346 decreased over time to the present. In contrast, concentrations of PBDEs increased towards the 347 present and were significantly correlated with concentrations of PBDFs in all three lakes. These 348 findings suggest that PBDEs do not appear to be a source of PXDD/Fs and that the sources of 349 PXDD/Fs are different to those of PBDFs. Moreover, while the correlation between PBDEs and 350 PBDFs implies that increased use of PBDEs has contributed substantially to environmental 351 contamination with PBDFs; examination of PBDF homologue patterns implies emissions from 352 combustion activities such as waste incineration and iron ore sintering are likely also important.

353 Concentrations of PBDEs in all samples are dominated by BDE-209 which is the main consitutent 354 of the Deca-BDE formulation most widely used in the UK. At two of the three lakes studied, the concentrations of BDE-209 were highest in the sediment layers dated to 2012 and 2009, rather than in the surface layer dated to 2015. This may indicate that recent bans and resrtictions on the 
manufacture and use of Deca-BDE may be starting to take effect and reduce concentrations in the environment.

\section{Acknowledgements}

361 The research leading to these results has received funding from the Marie Curie Actions of the 362 European Union's FP7 Programme under REA grant agreement \# 606857 (ELUTE project). The 363 analytical work was supported by the RECETOX research infrastructure (LM2018121). We thank 364 Ian Patmore for his help in the field, Aristide Ganci for field and lab-work assistance, and Alwyn 365 Fernandes for the kind gift of PXDD/F standards. This paper is dedicated to the memory of Dr 366 Leon Peters.

\section{Supplementary Data}

369 Supplementary data to this article can be found online at

\section{$371 \quad$ References}

372 1. Bromine Science and Environmental Forum (BSEF) 2003. Major Brominated Flame 373 Retardants Volume Estimates: Total Market Demand by Region in 2001, www.bsef.com $374 \quad$ (accessed $21^{\text {st }}$ January 2003).

2. Chattkittikunwong, W., Creaser, C. S. 1994. Bromo-, Bromochloro- and 376 Chloro-Dibenzo-p-Dioxins and Dibenzofurans in Incinerator Flyash. Chemosphere 29, $559-566$. 
3. Chen, S. J., Ma, Y. J., Wang, J., Tian, M., Luo, X-J., Chen, D., Mai, B-X. 2010 Measurement and human exposure assessment of brominated flame retardants in household products from South China. J. Hazard Mater. 176, 979-984.

4. Choi, J. W., Fujimaki, S., Kitamura, K., Hashimoto, S., Ito, H., Sakurai, T., Suzuki, N., Nagasaka, H., Tanabe, K., Sakai, S., Morita, M. 2003. Historical trends of PBDD/Fs, PBDEs, PCDD/Fs, and dioxin - like PCBs in sediment cores from Tokyo Bay. Organohalogen Compd. 61, 119-122.

5. Drage, D. S., Aries, E., Harrad., S. 2014. Studies into the formation of PBDEs and PBDD/Fs in the iron ore sintering process. Sci. Tot. Environ. 485-486, 497-507.

6. Ganci, A. P., Vane, C. H., Abdallah, M. A.-E., Moehring, T., Harrad, S. 2019. Legacy PBDEs and NBFRs in sediments of the tidal River Thames using liquid chromatography coupled to a high resolution accurate mass Orbitrap mass spectrometer. Sci. Tot. Environ. 658, 13551366.

7. Goto, A., Tue, N. M., Someya, M., Isobe, T., Takahashi, S., Tanabe, S., Kinisue, T. 2017. Spatio-temporal trends of polybrominated dibenzo- $p$-dioxins and dibenzofurans in archived sediments from Tokyo Bay, Japan. Sci.Tot. Environ. 599-600, 340-347.

8. Hagberg, J., Grahn, E., van Bavel, B., Lindström, G. 2005. Occurrence and levels of PCDD/Fs and PBDD/Fs in two Swedish lake sediments. Organohalogen Compd. 67, 20302032.

9. Hanari, N., Kannan, K., Okazawa, T., Kodavanti, P. R. S., Aldous, K. M., Yamashita, N. 2006. Occurrence of Polybrominated Biphenyls, Polybrominated Dibenzo-p-dioxins, and 
$400 \quad$ Mixtures. Environ. Sci. Technol. 40, 4400-4405.

401 10. Harrad, S., Hunter, S. 2006. Concentrations of Polybrominated Diphenyl Ethers in Air and 402 Soil on a Rural-Urban Transect Across a Major UK Conurbation. Environ. Sci. Technol. 40, $403 \quad 4548-4553$.

404 11. Hayakawa, K., Takatsuki, H., Watanabe, I., Sakai, S. 2004. Polybrominated diphenyl ethers 405 (PBDEs), polybrominated dibenzo-p-dioxins/dibenzofurans (PBDD/Fs) and 406 monobromo-polychlorinated dibenzo-p-dioxins/dibenzofurans (MoBPXDD/Fs) in the 407 atmosphere and bulk deposition in Kyoto, Japan. Chemosphere 57, 343-56.

408 12. Kannan, K., Watanabe, I., Giesy, J. P. 1998. Congener profile of polychlorinated/brominated 409 dibenzo-p-dioxins and dibenzofurans in soil and sediments collected at a former chlor-alkali 410 plant. Toxicol. Environ. Chem. 67, 135-146.

411 13. Law, R. J.; Herzke, D.; Harrad, S.; Morris, S.; Bersuder, P.; Allchin, C. R. 2008. Levels and 412 trends of brominated flame retardants in the European environment. Chemosphere 73, 223413241.

414 14. Kohler, M.. Zennegg, M. Bogdal, C., Gerecke, A. C., Schmid, P. V., Heeb, N., Sturm, M., 415 Vonmont, H., Kohler, H-P. E., Giger, W. 2008. Temporal Trends, Congener Patterns, and 416 Sources of Octa-, Nona-, and Decabromodiphenyl Ethers (PBDE) and 417 Hexabromocyclododecanes (HBCD) in Swiss Lake Sediments. Environ. Sci. Technol. 42, $418 \quad 6378-6384$. 
419 15. La Guardia, M. J., Hale, R. C., Harvey, E. 2006. Detailed Polybrominated Diphenyl Ether 420 (PBDE) Congener Composition of the Widely Used Penta-, Octa-, and Deca-PBDE Technical 421 Flame-retardant Mixtures. Environ. Sci. Technol. 40, 6247-6254.

16. Leung, A. O. W., Luksemburg, W. J., Wong, A. S., Wong, M. H. 2007. Spatial Distribution of Polybrominated Diphenyl Ethers and Polychlorinated Dibenzo-p-dioxins and Dibenzofurans in Soil and Combusted Residue at Guiyu, an Electronic Waste Recycling Site in Southeast China. Environ. Sci. Technol. 41, 2730-2737.

17. Lundstedt, S. 2016. Sources and levels of PBDD/Fs in the Swedish environment https://www.diva-portal.org/smash/get/diva2:945535/FULLTEXT01.pdf. (accessed March $3^{\text {rd }}$ 2020).

18. Ma, J., Kannan, K., Cheng, J., Hori, Y., Wu, Q., Wang, W. 2008. Concentrations, profiles, and estimated human exposures for polychlorinated dibenzo - $p$ - dioxins and dibenzofurans from electronic waste recycling facilities and a chemical industrial complex in Eastern China. Environ. Sci. Technol. 42, 8252 - 8259.

19. Ma, J., Addink, R., Yun, S. H., Cheng, J. P., Wang, W. H., Kannan K. 2009. Polybrominated dibenzo- $p$ - dioxins/dibenzofurans and polybrominated diphenyl ethers in soil, vegetation, workshop - floor dust, and electronic shredder residue from an electronic waste recycling facility and in soils from a chemical industrial complex in Eastern China. Environ. Sci. Technol. 43, $7350-7356$. 
20. Mai, B., Chen, S., Luo, X., Chen, L., Yang, Q., Sheng, G., Peng, P., Fu, J., Zeng, E. Y. 2005. Distribution of Polybrominated Diphenyl Ethers in Sediments of the Pearl River Delta and Adjacent South China Sea. Environ. Sci. Technol. 39, 3521-3527.

21. Myers, A. L., Mabury, S. A., Reiner, E. J. 2012. Analysis of mixed halogenated dibenzo-p-dioxins and dibenzofurans (PXDD/PXDFs) in soil by gas chromatography tandem mass spectrometry (GC-MS/MS). Chemosphere 87, 1063-1069.

22. Naturvårdsverket. 2011. Recycling and disposal of electronic waste - health hazards and environmental impacts.

6417. http://naturvardsverket.se/Documents/publikationer6400/978-91-620-6417-4.pdf （accessed March $3^{\text {rd } 2020)}$

23. Ohta, S., Nakao, T., Nishimura, H., Okumura, T., Aozasa, O., Miyata, H. 2002. Contamination levels of PBDEs, TBBPA, PCDD/Fs, PBDD/Fs and PXDD/Fs in the environment of Japan. Organohalogen Compd. 57, 57-60.

24. Patmore, I. R., Sayer, C. D., Goldsmith, B., Davidson, T. A., Rawcliffe, R., Salgado, J. 2014. Big Ben: A new wide-bore piston corer for multi-proxy palaeolimnology. J. Paleolimnol. 51, $79-86$.

25. Ramu, K., Isobe, T., Takahashi, S., Subramanian, A., Parthasarathy, P., Tanabe S. 2008. Brominated flame retardants and dioxins in soil from electronic waste recycling sites in India. Organohalogen Compd. 70, 2058 - 2061.

26. Ren, M., Peng, P., Cai, Y., Chen, D., Zhou, L., Chen, P., Hu, J. 2011. PBDD/F impurities in some commercial deca-BDE. Environ. Pollut. 159, 1375-1380. 
27. Takigami, H., Sakai, S., Brouwer, A. 2005. Bio/chemical Analysis of Dioxin-like Compounds in Sediment Samples from Osaka Bay, Japan. Environ. Technol. 26, 459-70.

28. Terauchi, H., Takahashi, S., Lam, P. K. S., Min, B-Y., Tanabe, S. 2009. Polybrominated, polychlorinated and monobromo-polychlorinated dibenzo-p-dioxins/dibenzofurans and dioxin-like polychlorinated biphenyls in marine surface sediments from Hong Kong and Korea. Environ. Pollut. 157, 724-730.

29. Tue, N. M., Takahashi, S., Subramanian, A., Sakai, S., Tanabe, S. 2013. Environmental contamination and human exposure to dioxin-related compounds in e-waste recycling sites of developing countries. Environ. Sci. Proc. Imp. 15, 1326-1331.

30. Van den Berg, M., Denison, M. S., Birnbaum, L. S., DeVito, M. J., Fiedler, H., Falandysz, J., Rose, M., Schrenk, D., Safe, S., Tohyama, C., Tritscher, A., Tysklind, M., Peterson, R. E. 2013. Polybrominated Dibenzo-p-Dioxins, Dibenzofurans, and Biphenyls: Inclusion in the Toxicity Equivalency Factor Concept for Dioxin-Like Compounds. Toxicol. Sci. 133, 197208.

31. Vane, C. H., Ma, Y-J., Chen, S-J., Mai, B-X. Increasing polybrominated diphenyl ether (PBDE) contamination in sediment cores from the inner Clyde Estuary, UK. 2010. Environ. Geochem. Hlth. 32, 13-21.

32. Wall, R. J., Fernandes, A., Rose, M., Bell, D. R., Mellor, I. R. 2015. Characterisation of chlorinated, brominated and mixed halogenated dioxins, furans and biphenyls as potent and as partial agonists of the Aryl hydrocarbon receptor. Environ. Int. 76, 49-56.

33. Wang, L-C., Hsi, H-C., Wang, Y-F., Lin, S-L, Chang-Chien, G-P. 2010. Distribution of polybrominated diphenyl ethers (PBDEs) and polybrominated dibenzo-p-dioxins and 
dibenzofurans (PBDD/Fs) in municipal solid waste incinerators. Environ. Pollut. 158, 1595602.

483

34. Wang, M., Liu, G., Jiang, X., Liu, W., Li, L., Li, S., Zheng, M., Zhan, J. 2015. Brominated dioxin and furan stack gas emissions during different stages of the secondary copper smelting process. Atmos. Pollut. Res. 6, 464-468.

35. Weber, R., Kuch, B. 2003. Relevance of BFRs and thermal conditions on the formation pathways of brominated and brominated-chlorinated dibenzodioxins and dibenzofurans. Environ. Int. 29, 699- 710.

36. Webster, L., Russell, M., Adefehinti, F., Dalgarno, E. J., Moffat, C. F. 2008. Preliminary assessment of polybrominated diphenyl ethers (PBDEs) in the Scottish aquatic environment, including the Firth of Clyde. J. Environ. Monit. 10, 463-473.

37. Yang, C., Rose, N.L., Turner, S.D., Yang, H., Goldsmith, B., Losada, S., Barber, J. L., Harrad, S. 2016. Hexabromocyclododecanes, polybrominated diphenyl ethers, and polychlorinated biphenyls in radiometrically dated sediment cores from English lakes, 1950-present. Sci. Tot. Environ. 541, 721-728.

38. Yu, X., Zennegg, M., Engwall, M., Rotander, A., Larsson, M., Wong, M. H., Weber, R. 2008. E-Waste Recycling Heavily Contaminates a Chinese City with Chlorinated, Brominated and Mixed Halogenated Dioxins. Organohalogen Compd. 70, 813-816.

39. Zegers, B. N., Lewis, W. E., Booij, K., Smittenberg, R. H., Boer, W., de Boer, J., Boon, J. P. 2003. Levels of polybrominated diphenyl ether flame retardants in sediment cores from Western Europe. Environ. Sci. Technol. 37, 3803-3807. 
40. Zennegg, M., Yu, X., Wong, M. H., Weber, R. 2009. Fingerprints of Chlorinated, Brominated and Mixed Halogenated Dioxins at Two E-Waste Recycling Sites in Guiyu/China. Organohalogen Compd. 71, 2248-2252.

41. Zhang, X-L., Luo, X-J., Chen, S-J., Wu, J-P., Mai, B-X. 2009. Spatial distribution and vertical profile of polybrominated diphenyl ethers, tetrabromobisphenol A, and decabromodiphenylethane in river sediment from an industrialized region of South China. Environ. Pollut. 157, 1917-1923

42. Zhou, L., Li, H., Yu, Z., Ren, M., Zeng, X., Peng, P., Sheng, G., Fu, J. 2012. Chlorinated and brominated dibenzo-p-dioxins and dibenzofurans in surface sediment from Taihu Lake, China. J. Environ. Monit. 14, 1935-1942. 


\begin{tabular}{|c|c|c|c|}
\hline Matrix, Location & $\Sigma$ IPBDD/F & $\Sigma$ PBDE & Reference \\
\hline \multicolumn{4}{|l|}{ Fresh water sediments } \\
\hline Edgbaston Pool, UK & 7.1 & 210 & This Study \\
\hline Holt Hall Lake, UK & 0.49 & 18 & This Study \\
\hline Wake Valley Pond, UK & 0.49 & 21 & This Study \\
\hline Edgbaston Pool, UK ${ }^{\mathrm{a}}$ & - & 120 & Yang et al, 2016 \\
\hline Holt Hall Lake, $\mathrm{UK}^{\mathrm{a}}$ & - & 10 & Yang et al, 2016 \\
\hline Wake Valley Pond, $\mathrm{UK}^{\mathrm{a}}$ & - & 9.8 & Yang et al, 2016 \\
\hline Surficial Sediments, River Thames, UK & - & 180 (mean) & Ganci et al, 2019 \\
\hline Clyde Estuary, UK (core slices) & - & $1-2,600$ & Vane et al, 2010 \\
\hline Scotland, UK (core slices) & - & $2.3-98,000$ & Webster et, 2008 \\
\hline Rural/urban lakes, Sweden & $0.44-0.54$ & - & Hagberg et al, 2005 \\
\hline Urban river, Sweden & $0.41-1.7$ & $29-62$ & Lundstedt, 2016 \\
\hline Rural lake Sweden & $0.082-0.085$ & $4.4-16$ & Lundstedt, 2016 \\
\hline Urban lake, China & $0.00048-0.0057$ & - & Zhou et al, 2012 \\
\hline Stream at dump site, Peru & $0.012-0.074$ & $3.7-6.1$ & Naturvårdsverket, 2011 \\
\hline Lake, industrial area, Thailand & $0.037-1.5$ & $3.4-58$ & Naturvårdsverket, 2011 \\
\hline \multicolumn{4}{|l|}{ Marine sediments } \\
\hline Hong Kong/Korea & nd. -0.46 & - & Terauchi et al, 2009 \\
\hline Tokyo Bay, Japan & $0.0052-0.070$ & $10-78,050$ & Choi et al, 2003 \\
\hline Osaka, Japan & $0.0041-0.077$ & $8.0-352$ & Ohta et al, 2002 \\
\hline Osaka, Japan & $0.0024-0.59$ & $53-910$ & Takigami et al, 2005 \\
\hline Coastal and offshore, Sweden & $0.050-10$ & - & Lundstedt, 2016 \\
\hline \multicolumn{4}{|l|}{ Rural Soil } \\
\hline Lanna, Sweden & $0.028-0.054$ & $0.065-1.3$ & Lundstedt, 2016 \\
\hline \multicolumn{4}{|l|}{ Urban soil } \\
\hline Umeå and Norrköping, Sweden & $0.0011-0.22$ & $0.18-66$ & Lundstedt, 2016 \\
\hline Bangalore and Chennai, India & $0.0060-0.31$ & - & Ramu et al, 2008 \\
\hline Kyoto, Japan & 0.28 & - & Hayakawa et al, 2004 \\
\hline Industrial area, China & nd. -0.43 & $2.03-269$ & Ma et al, 2008; Ma et al, 2009 \\
\hline Industrial area, Thailand & $0.019-0.16$ & $1.8-13$ & Naturvårdsverket, 2011 \\
\hline Dump site, Peru & $0.0086-0.32$ & $3.6-92$ & Naturvårdsverket, 2011 \\
\hline
\end{tabular}


516 Table 2: Concentrations (pg/g OC) of PXDD/Fs in Sediment Core Slices from Wake Valley Pond and Holt Hall Lake with Comparative

517 Data from Osaka Bay, Japan

\begin{tabular}{|c|c|c|c|c|c|c|c|c|c|c|c|c|c|}
\hline Location & Congener/ Homologue/ Year & 2015 & 2009 & 2005 & 2004 & 1999 & 1993 & 1985 & 1977 & 1969 & 1965 & 1954 & 1935 \\
\hline Wake Valley Pond & 2-Br-7,8-CDD & 0.023 & 0.16 & 0.24 & & 0.32 & 0.4 & 0.035 & & & 0.079 & $<0.032$ & \\
\hline Holt Hall Lake & 2-Br-7,8-CDD & 1.1 & 2.8 & & 2.6 & 3.4 & & 1.1 & $<0.025$ & $<0.024$ & & $<0.021$ & $<0.021$ \\
\hline Wake Valley Pond & Total Br-2CDD & 0.73 & 1.9 & 1.9 & & 2.7 & 2.3 & 3.6 & & & 0.8 & 9.3 & \\
\hline Holt Hall Lake & Total Br-2CDD & 1.8 & 4.1 & & 4.0 & 5.3 & & 2.2 & 11 & 7.1 & & 2.3 & $<0.021$ \\
\hline Wake Valley Pond & \begin{tabular}{|l|} 
2-Br-3,7,8-CDD \\
\end{tabular} & 0.081 & $<0.028$ & $<0.027$ & & 0.12 & 0.22 & 0.22 & & & 0.29 & $<0.047$ & \\
\hline Holt Hall Lake & 2-Br-3,7,8-CDD & 0.02 & 0.049 & & 0.054 & 0.16 & & 0.08 & 1.4 & $<0.035$ & & $<0.031$ & $<0.03$ \\
\hline Osaka Bay, Japan ${ }^{\mathrm{a}}$ & 2-Br-3,7,8-CDD & \multicolumn{12}{|c|}{$0.84-6.5$} \\
\hline Wake Valley Pond & Total Br-3CDD & 1.5 & 2.2 & 2.8 & & 3.8 & 3 & 3.5 & & & 6.2 & 9.3 & \\
\hline Holt Hall Lake & Total Br-3CDD & 0.77 & 2.1 & & 2.4 & 2.7 & & 2.4 & 18 & $<0.027$ & & $<0.019$ & $<0.018$ \\
\hline Wake Valley Pond & 2,3-Br-7,8-CDD & $<0.015$ & $<0.017$ & $<0.016$ & & $<0.016$ & $<0.017$ & $<0.016$ & & & $<0.016$ & $<0.029$ & \\
\hline Holt Hall Lake & 2,3-Br-7,8-CDD & $<0.013$ & 0.095 & & 0.062 & $<0.018$ & & 0.034 & $<0.022$ & $<0.021$ & & $<0.019$ & $<0.018$ \\
\hline Osaka Bay, Japan ${ }^{a}$ & \begin{tabular}{|l|} 
2,3-Br-7,8-CDD \\
\end{tabular} & \multicolumn{12}{|c|}{ Not detected } \\
\hline Wake Valley Pond & \begin{tabular}{|l|} 
Total $2 B r-2 C D D$ \\
\end{tabular} & 0.48 & 0.64 & 0.87 & & 1.2 & 1.5 & 1.8 & & & 1.2 & 4.4 & \\
\hline Holt Hall Lake & Total 2Br-2CDD & 0.33 & 0.79 & & 0.82 & 1.1 & & 0.97 & 5.0 & 2.2 & & 0.62 & $<0.017$ \\
\hline Wake Valley Pond & 1-Br-2,3,7,8-CDD + 2-Br-1,3,7,8-CDD & $<0.018$ & $<0.021$ & 0.37 & & $<0.02$ & $<0.021$ & $<0.02$ & & & $<0.021$ & $<0.032$ & \\
\hline Holt Hall Lake & 1-Br-2,3,7,8-CDD + 2-Br-1,3,7,8-CDD* & $<0.016$ & $<0.019$ & & $<0.02$ & $<0.023$ & & $<0.027$ & $<0.028$ & $<0.027$ & & $<0.024$ & $<0.023$ \\
\hline Osaka Bay, Japan ${ }^{a}$ & 1-Br-2,3,7,8-CDD & \multicolumn{12}{|c|}{ Not detected } \\
\hline Wake Valley Pond & Total Br-4CDD & 1.7 & 1.8 & 2.8 & & 3.8 & 5.9 & 4.6 & & & 7 & 5.7 & \\
\hline Holt Hall Lake & Total Br-4CDD & 0.47 & 1.9 & & 1.0 & 1.9 & & $<0.021$ & $<0.022$ & $<0.021$ & & 0.71 & $<0.018$ \\
\hline Wake Valley Pond & 2-Br-3,6,7,8,9-CDD & $<0.015$ & $<0.017$ & $<0.016$ & & $<0.016$ & $<0.017$ & $<0.016$ & & & $<0.016$ & $<0.029$ & \\
\hline Holt Hall Lake & 2-Br-3,6,7,8,9-CDD & $<0.013$ & $<0.015$ & & $<0.016$ & $<0.018$ & & 0.6 & $<0.022$ & $<0.021$ & & $<0.019$ & $<0.018$ \\
\hline Osaka Bay, Japan $^{\mathrm{a}}$ & 2-Br-3,6,7,8,9-CDD & \multicolumn{12}{|c|}{ Not detected -0.32} \\
\hline Wake Valley Pond & Total Br-5CDD & 1 & 0.82 & 3.5 & & 2.2 & 5.1 & 7 & & & 7.5 & 15 & \\
\hline Holt Hall Lake & Total Br-5CDD & $<0.018$ & 0.11 & & $<0.01$ & $<0.012$ & & 0.6 & $<0.022$ & $<0.021$ & & $<0.019$ & $<0.018$ \\
\hline
\end{tabular}

Peters et al 2020 Page 27 of 31 


\begin{tabular}{|c|c|c|c|c|c|c|c|c|c|c|c|c|c|}
\hline Location & Congener/ Homologue/ Year & 2015 & 2009 & 2005 & 2004 & 1999 & 1993 & 1985 & 1977 & 1969 & 1965 & 1954 & 1935 \\
\hline Wake Valley Pond & 2-Br-7,8-CDF & 0.77 & 1 & 0.88 & & $<0.01$ & 2 & 2.7 & & & $<0.01$ & $<0.018$ & \\
\hline Holt Hall Lake & 2-Br-7,8-CDF & $<0.008$ & $<0.01$ & & $<0.01$ & $<0.012$ & & 0.53 & $<0.014$ & $<0.013$ & & $<0.012$ & $<0.012$ \\
\hline Wake Valley Pond & Total Br-2CDF & 6.9 & 16 & 16 & & 26 & 17 & 25 & & & 22 & 62 & \\
\hline Holt Hall Lake & Total Br-2CDF & 4.7 & 7.9 & & 7.7 & 12 & & 9.6 & 88 & 89 & & 15 & 9.5 \\
\hline Wake Valley Pond & $2-\mathrm{Br}-6,7,8-\mathrm{CDF}+3-\mathrm{Br}-2,7,8-\mathrm{CDF}^{*}$ & $<0.012$ & 0.13 & 0.17 & & 0.3 & 0.65 & 0.46 & & & 0.076 & $<0.023$ & \\
\hline Holt Hall Lake & $2-\mathrm{Br}-6,7,8-\mathrm{CDF}+3-\mathrm{Br}-2,7,8-\mathrm{CDF}^{*}$ & 0.07 & 0.28 & & 0.18 & 0.40 & & 1.3 & 5.1 & $<0.017$ & & 0.63 & $<0.015$ \\
\hline Osaka Bay, Japan ${ }^{\text {a }}$ & $3-\mathrm{Br}-2,7,8-\mathrm{CDF}$ & \multicolumn{12}{|c|}{ Not detected-2.0 } \\
\hline Wake Valley Pond & Total Br-3CDF & 4.3 & 6 & 6.4 & & 8.4 & 8.7 & 10 & & & 11 & 57 & \\
\hline Holt Hall Lake & Total Br-3CDF & 2.5 & 4.8 & & 5.3 & 8.8 & & 5.0 & 44 & 49 & & 6.6 & 3.1 \\
\hline Wake Valley Pond & $1-\mathrm{Br}-2,3,7,8-\mathrm{CDF}$ & 0.022 & $<0.014$ & 0.047 & & 0.042 & 0.66 & $<0.012$ & & & $<0.012$ & $<0.021$ & \\
\hline Holt Hall Lake & 1-Br-2,3,7,8-CDF & $<0.009$ & $<0.011$ & & $<0.012$ & $<0.014$ & & $<0.016$ & $<0.017$ & $<0.016$ & & $<0.014$ & $<0.014$ \\
\hline Osaka Bay, Japan ${ }^{\mathrm{a}}$ & 1-Br-2,3,7,8-CDF & \multicolumn{12}{|c|}{ Not detected } \\
\hline Wake Valley Pond & Total Br-4CDF & 1.5 & 1.6 & 2.6 & & 3.6 & 6.4 & 5.8 & & & 2 & 20 & \\
\hline Holt Hall Lake & Total Br-4CDF & 1.8 & 5.0 & & 2.4 & 5.2 & & 0.81 & 7.3 & $<0.016$ & & 3.5 & 4.4 \\
\hline Wake Valley Pond & $\sum$ PXDD & 5.4 & 7.5 & 12 & & 14 & 18 & 20 & & & 23 & 43 & \\
\hline Holt Hall Lake & $\sum$ PXDD & 3.3 & 9.1 & & 8.2 & 11 & & 6.0 & 34 & 9.3 & & 7.1 & $<0.03$ \\
\hline Wake Valley Pond & $\sum$ PXDF & 13 & 24 & 25 & & 38 & 32 & 41 & & & 34 & 140 & \\
\hline Holt Hall Lake & $\sum$ PXDF & 9.0 & 18 & & 15 & 26 & & 15 & 140 & 140 & & 25 & 17 \\
\hline Wake Valley Pond & $\sum \mathrm{PXDD} / \mathrm{F}$ & 18 & 31 & 37 & & 51 & 50 & 61 & & & 57 & 180 & \\
\hline Holt Hall Lake & $\sum \mathrm{PXDD} / \mathrm{F}$ & 12 & 27 & & 24 & 37 & & 21 & 170 & 150 & & 32 & 17 \\
\hline
\end{tabular}


Figure 1: Temporal Trends in Concentrations (ng/g OC) of $\Sigma$ PBDE, $\Sigma$ PBDF, and $\Sigma$ PXDD/F in 3 English Lake Sediment Cores

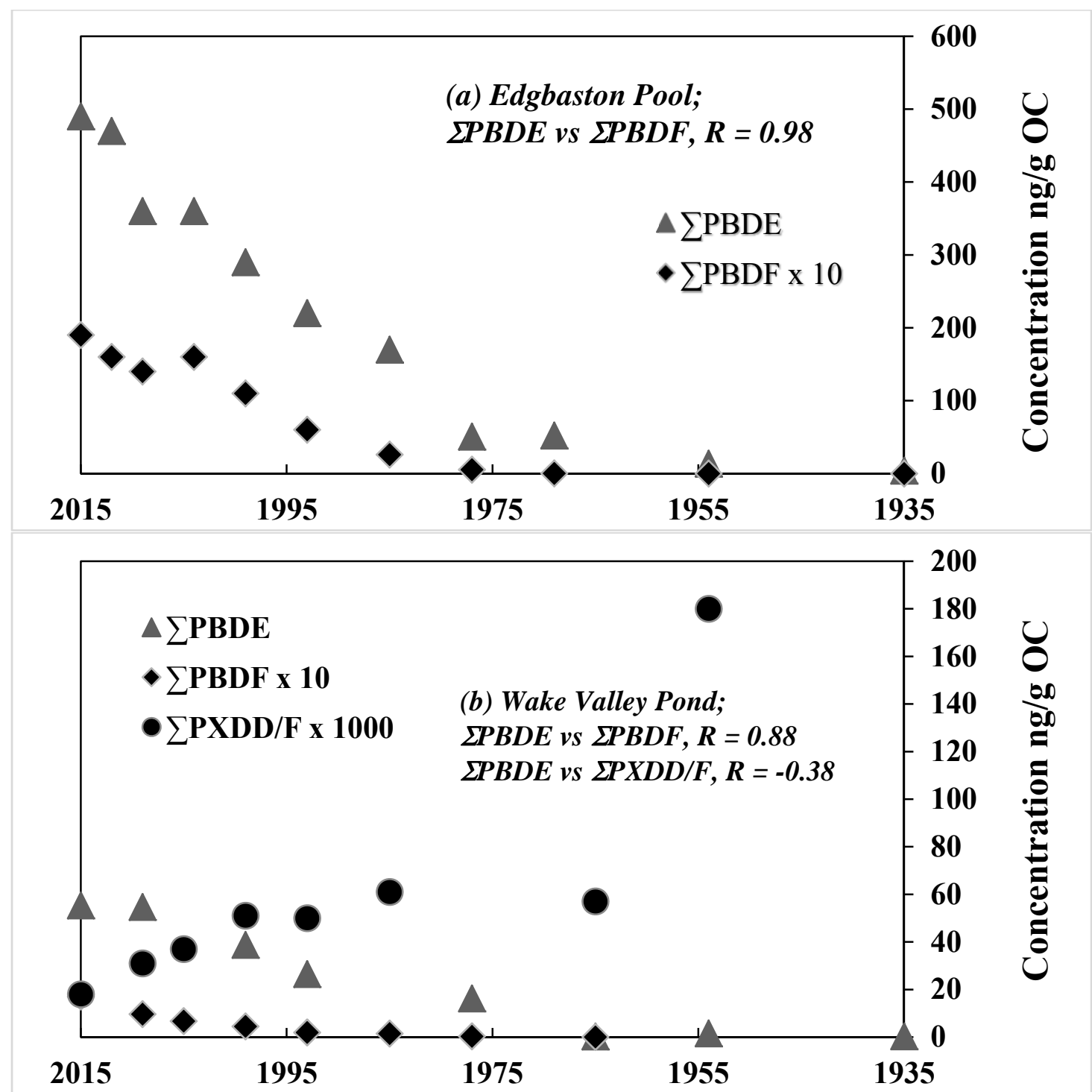


Figure 2: Temporal Trends in Relative Contributions of PBDF Homologues to $\Sigma$ PBDF Concentrations in 3 English Lake Sediment Cores

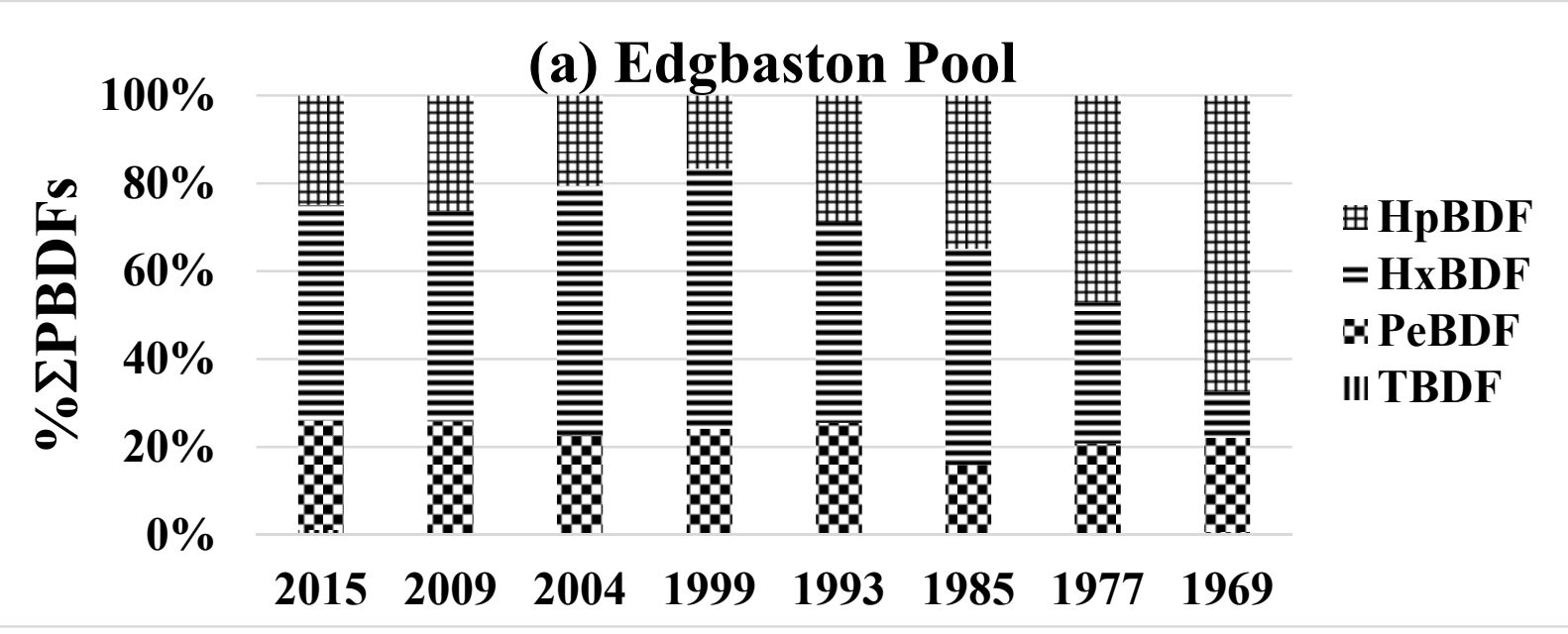

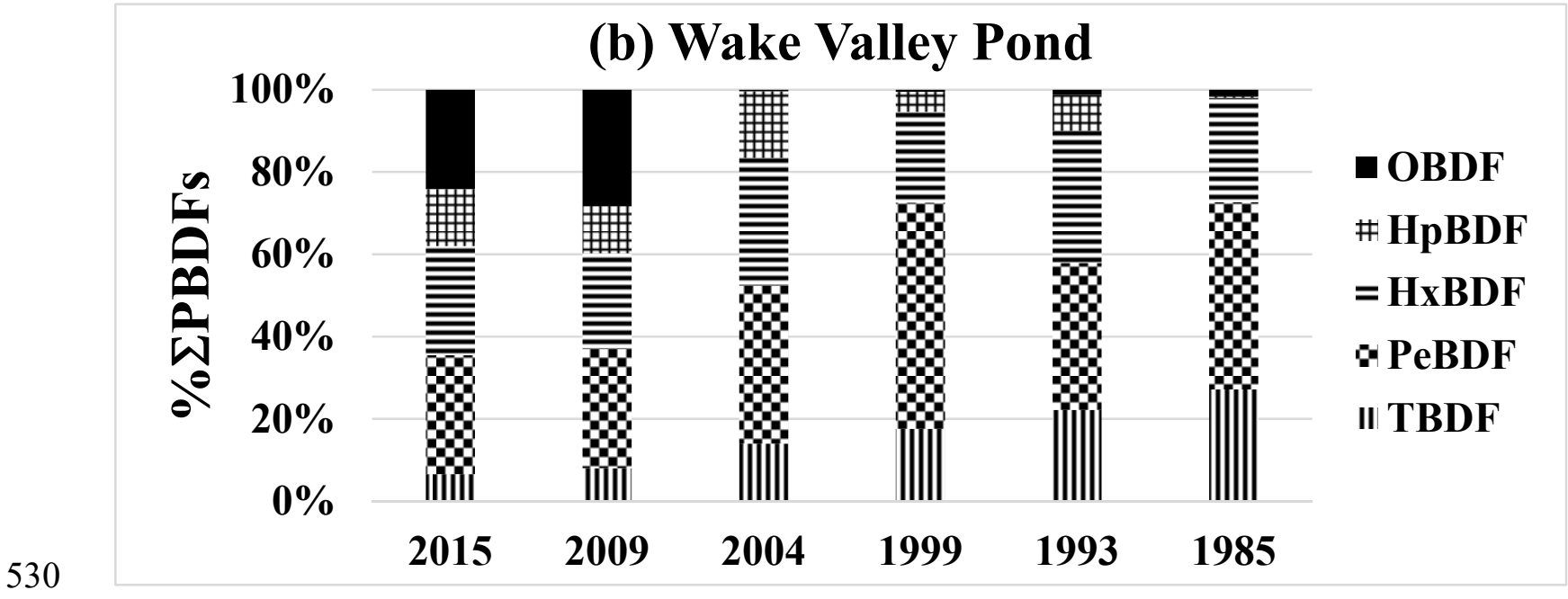


(c) Holt Hall Lake

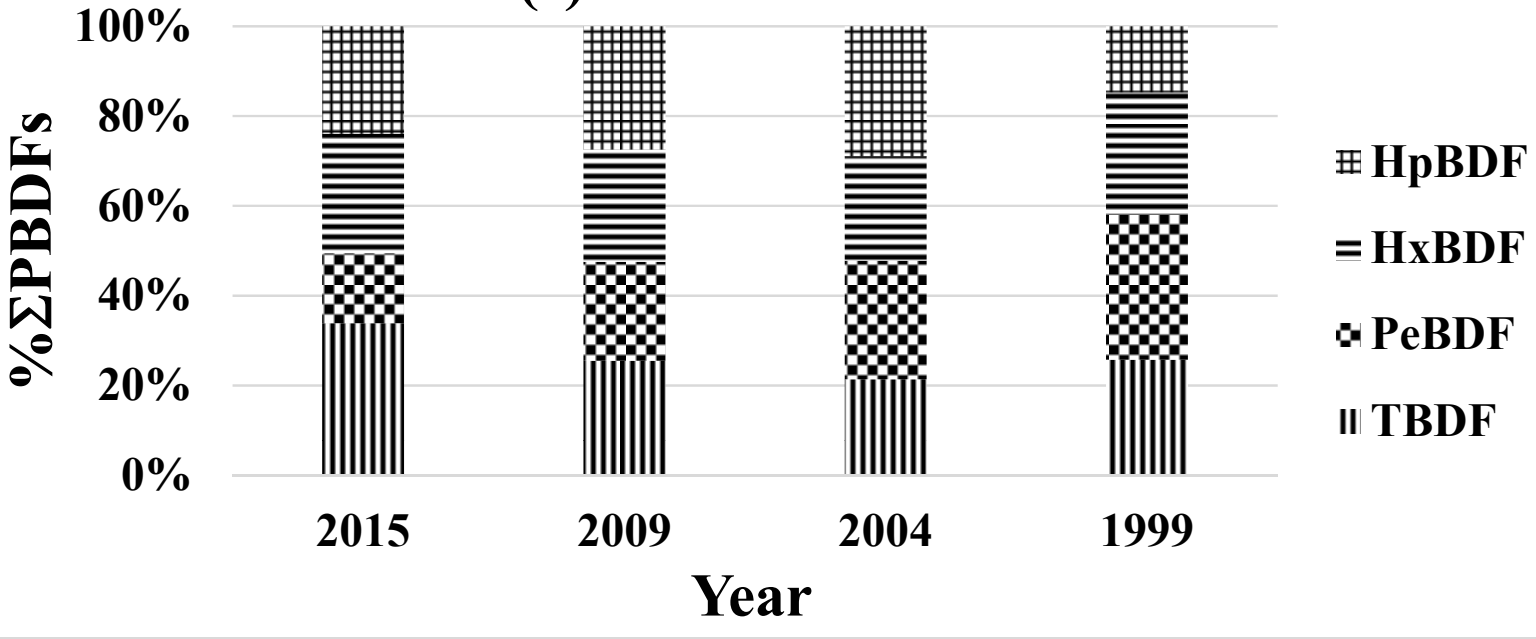

